\title{
An audit of teenagers who had not succeeded in elementary school: a retrospective case review
}

This article was published in the following Dove Press journal:

Clinical Audit

9 March 2012

Number of times this article has been viewed

\section{Ulla Ek'}

Joakim Westerlund ${ }^{2}$

Catarina Furmark ${ }^{2}$

Elisabeth Fernell ${ }^{3,4}$

'Department of Special Education, ${ }^{2}$ Department of Psychology, Stockholm University, Stockholm, Sweden; ${ }^{3}$ Research and Development Centre, Skaraborg Hospital, Skövde, Sweden; ${ }^{4}$ Gillberg Neuropsychiatry Centre, Sahlgrenska Academy, Gothenburg University, Gothenburg, Sweden
Correspondence: Ulla Ek Department of Special Education, Stockholm University, SE-106 91 Stockholm, Sweden

Tel +46 8 I207 6455

Email ulla.ek@specped.su.se
Objective: The aim was to perform a retrospective case review of pupils who had not succeeded in elementary school, in order to analyze barriers at individual and system levels.

Methods: Forty-five pupils, aged 16-20 years, who had not qualified for senior high school, were consecutively assessed within the school health unit to determine their cognitive function, school history, measures taken, previous assessments, and diagnoses given.

Results: School health records revealed early problems with learning, reading, mathematics, and attention, but very few students had received an appropriate diagnosis. Our review and assessment when all the data had been compiled demonstrated that the vast majority (96\%) of participants had clear developmental problems. Attention problems or full attention deficit/ hyperactivity disorder dominated. About half of the students reported extensive truancy. Mean intelligence quotient in the study group was 83.9, about 1 standard deviation below the mean. Fluid intelligence was significantly superior to crystallized intelligence.

Conclusion: Screening and identification are needed throughout the school years of children who present symptoms that could interfere with their academic achievement. Intervention needs to be based on skilled assessment, with consideration given to each individual's broad panorama of cognitive deficits and assets, as well as concomitant social adversities that may underlie their school failure. Since there can be a significant negative impact of limited educational opportunities on future socioeconomic outcomes, the question of who is at risk is important both for affected individuals and more generally for public health.

Limitations: The study group was small and may not have been fully representative. In spite of limited confidence about generalizing from the results, the findings call for reflection.

Keywords: school failure, cognitive, ADHD, fluid, crystallized, intelligence

\section{Introduction}

There is worldwide scientific awareness and deep concern regarding the school situation for pupils with learning difficulties that are related to attention and other cognitive deficits. ${ }^{1-7}$ Academic and behavior-related problems constitute a significant public health burden and may signal major psychological, economic, and social problems. ${ }^{7}$ Attention problems are a major factor behind academic underachievement and should always be assessed in children and adolescents with a history of school failure and dropping out and with externalizing and internalizing psychiatric problems. ${ }^{8-11}$

However, aspects relating to identification, screening, and intervention are not sufficiently discussed among professionals. Furthermore, despite the vast scientific literature on the consequences of attention deficit/hyperactivity disorder (ADHD) and of attention symptoms not fully meeting all criteria for ADHD, ie, subthreshold ADHD, 
implementation of this knowledge and of how to adapt school education for these pupils is far from satisfactory.

To qualify for further studies in senior high school in Sweden, a student needs to have passed in three core subjects: the Swedish language, English, and mathematics. The final grade, computed as the sum of the grades for 16 subjects, that is required for admission to a program in senior high school depends on the number of applicants competing and varies according to the program type. In Sweden, about 14,000 pupils (12\%) finish compulsory schooling (Grade 9 at age 16 years) every year without having passed one or more of these core subjects. ${ }^{12}$ Consequently, they cannot go on to study at senior high school. These pupils are offered further studies in a special program (Individual Program), with the aim being to gain access to a senior high school program after 1 or 2 years. In addition to the $12 \%$ not having passed, a further $6 \%$ drop out from ordinary upper secondary school/ senior high school. ${ }^{12}$

Pupils with mild intellectual disability (ID) (intelligence quotient $[\mathrm{IQ}]<70$ ) are offered a special program at a senior high school for individuals with mild ID. However, pupils with borderline intellectual functioning (BIF) (IQ 70-85) with or without significant attention problems are usually not offered any specially adapted education.

We have previously reported results from a longitudinal population-based study of pupils with various degrees of attention, behavior, and learning problems. ${ }^{13}$ Pupils with ADHD and those with behavioral and/or learning problems, including milder attention problems, achieved a significantly lower overall mean final grade than the comparison group, which consisted of pupils without such problems, and they passed in the three core subjects to a much lower extent. We did not find a significant difference in academic outcome between those with marked problems (ie, ADHD) and those with somewhat less marked attention problems.

As part of a quality project being undertaken among schools in Stockholm, Sweden, one of the senior high schools with a large Individual Program asked for a review to examine underlying problems - in terms of academic, cognitive, and social factors - in their group of pupils. The aim of this study was to present data from that review and to discuss what general conclusions could be drawn concerning the importance of screening, identification, and intervention.

\section{Materials and methods}

The group of participants consisted of pupils in one senior high school Individual Program with approximately 200 enlisted pupils in Grades 1 and 2. All these pupils were invited to take part in an assessment procedure and 45 pupils applied. They all asked for possible explanations as to why they had not succeeded in school and the majority wanted to discuss the problems that they experienced with adaptation to daily life, their current educational situation, and those that they might expect to encounter in their future vocational life.

All assessments were consecutively carried out within the regular school health service. The proportion of males to females in the school was $46 \%$ to $54 \%$, and $33 \%$ had an immigrant background.

The study group consisted of 45 pupils (22 male and 23 female). Their mean age was 18.01 years (standard deviation [SD] 0.95 years), with a range of 16-20 years. Twenty-four of the 45 pupils (53\%), nine male and 15 female, had an immigrant background (ie, with at least one parent born abroad), and eleven of them had also been born abroad. Nineteen of these 24 pupils had been in a Swedish school since their first year in the academic system, while five had arrived later (at 8, 9, 11, 13, and 16 years of age). This meant that 40 of the 45 pupils had had their entire schooling in the Swedish school system.

Seventeen had been educated in an ordinary class and 24 had had their education in small groups or classes with special resources for part of or throughout their school years. Two had been in a special school for pupils with ID, and two came to Sweden late in their school education. Thirty of the 45 pupils (67\%) had divorced parents, and a further two lived with relatives.

All pupils were interviewed through a structured protocol to determine their school history and to obtain information on their current school and their home situation. Such information was also collected from teachers and from parents when the participating pupil and the parent(s) agreed to it. The interview included questions about truancy, bullying, and previous assessment by a child and adolescent psychiatrist, by a speech and language pathologist, or at a neuropediatric clinic. School health records were collected and reviewed by an experienced neuropediatrician in collaboration with the school doctor, with a special focus on the participants' pediatric background, difficulties described during the school years, teachers' reports, previous assessments, earlier diagnoses and interventions, or measures taken at school.

The main cognitive test used was the third edition of the Wechsler Intelligence Scale for Children (WISC-III). ${ }^{14}$ The matrices from the Wechsler Adult Intelligence Scale III ${ }^{15}$ and also, in some cases, Raven's Standard Progressive Matrices 
test, ${ }^{16}$ were used as supplementary tests to validate and establish or confirm the cognitive level of some pupils who had only had a few years in a Swedish school. These tests are nonverbal, and as such could be considered more "culture free" than those with a verbal component. In one pupil, who had arrived in Sweden at the age of 16 years, the nonverbal scales of the WISC-III and the matrices from the Wechsler Adult Intelligence Scale were used. All 45 pupils were assessed by one research and clinical psychologist or by a supervised trainee psychologist.

For the WISC-III, full-scale IQ was calculated and analyzed, as well as scaled scores (mean 10, SD 3) for 12 subtests. Indices for "crystallized intelligence" (referring to the possession of a general fund of knowledge that can be used when solving problems based on information, vocabulary, and comprehension) and "fluid intelligence" (which refers to an ability to conduct logical reasoning when solving problems, based on arithmetic, picture completion, and object assembly) were also calculated.

After the assessments, all available data were discussed in a case conference with the appropriate school health staff. Final diagnoses were assigned as "best-possible estimates based on consensus" using all available information. Feedback was given orally to parents/pupils and teachers and complemented with a written report as agreed beforehand. In cases where further assessments were necessary to reach a conclusion or to confirm a diagnosis, the school doctor referred the participant to a child and adolescent psychiatric or pediatric outpatient clinic or to an adult mental health service.

\section{Results \\ Data from interviews and school health records}

For 17 of the 45 pupils, the first reported difficulties in school concerned problems with learning, reading, and/or mathematics. For another 22, attention problems with or without externalizing behavior were reported to be the main source of concern. Four of these had diagnosed ADHD. Another four had had internalizing behavior recorded as their main problem. For the two remaining pupils, we could not identify a specific problem in the records or during the interviews. Pupils with reported attention problems had been placed in small groups or special resource classes, while pupils with reported cognitive or learning problems (affecting their reading, writing, and/or mathematics) had generally been educated in ordinary classes $\left(\chi_{4}^{2}=9.90\right.$, $P=0.031$ ) (Statistical Package for the Social Sciences Exact Tests [IBM, Armonk, NY]).
In 28 of the 45 cases (62\%), school problems had already been recorded during the first, second, or third school years. For the remaining 17 pupils, seven had had their problems identified in Grade 4, three in Grade 5, three in Grade 6, three in Grade 7, and for one pupil we were not able to find any information about the first recorded problems.

Twenty pupils reported extensive truancy, in some cases over a period of one or two full school years. Ten reported being heavily bullied (eight female and two male). This information had not been noted in the school health records.

A previous assessment had been performed for 21 of the 45 pupils: seven at the school health unit, five at a neuropediatric unit, six at a child and adolescent psychiatric outpatient clinic, and three by a speech and language pathologist. These assessments had resulted in diagnoses being specified for 14 pupils: two had dyslexia, two mild ID, four Asperger's syndrome, four ADHD, one anxiety/depression, one had autistic features and a verified $22 \mathrm{q} 11$ deletion syndrome, and for seven pupils no specific disorder had been diagnosed. Twenty-four pupils had not had any previous assessment made.

\section{Cognitive data, main problems, and diagnoses at final assessment}

All 45 pupils underwent a complete cognitive assessment. Mean total IQ, at 83.9 (SD 17.95), was within the normal range. Three of the 45 pupils had BIF, revealed in the present cognitive assessment, as their main problem. Four were found to have mild ID.

The highest scores were found on the subscales reflecting verbal comprehension and common sense (similarities, comprehension, and picture completion), and the lowest scores were found on subscales reflecting working memory, planning, fluency, and vocabulary (information, vocabulary, arithmetic, coding, block design, and symbol search) (Figure 1).

A paired-samples $t$-test showed that mean fluid intelligence (9.02, SD 2.89) was significantly higher than mean crystallized intelligence (7.08, SD 2.82): $t_{43}=4.17, P<0.001$, $\mathrm{d}=0.68$. Pupils with an immigrant background had lower scores on both crystallized and fluid intelligence. A $2 \times 2$ analysis of variance with type of intelligence (crystallized/ fluid) as a within-subject factor, immigrant background (yes/no) as a grouping factor, and mean intelligence score as the dependent variable revealed a significant main effect $\left(\mathrm{F}_{1,42}=15.31, P<0.001, \eta^{2}=0.267\right)$ (Figure 2$)$.

Twenty-six pupils were found to have very strong indications of attention deficits/ADHD; four of these 26 pupils 


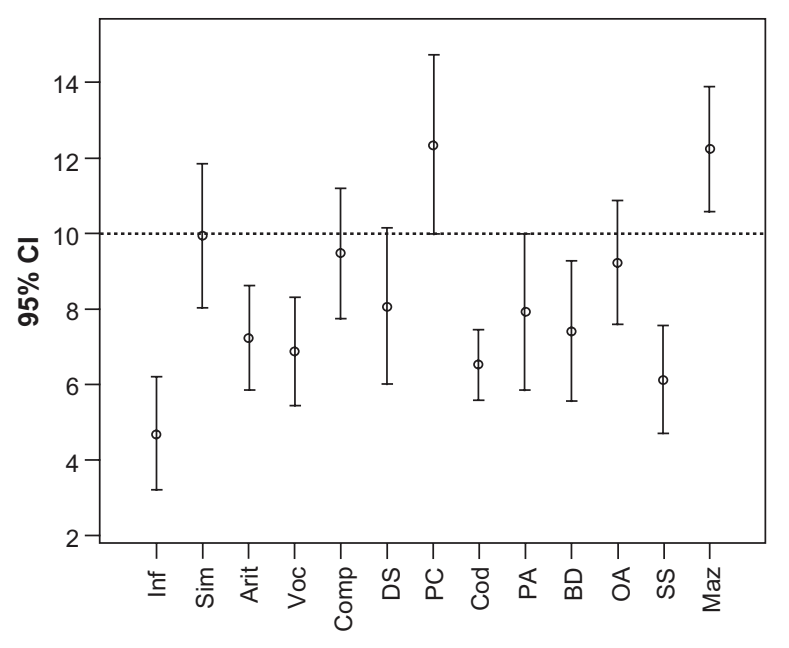

Figure I Means and confidence intervals for scaled scores on the 13 Wechsler Intelligence Scale for Children subtests.

Abbreviations: $\mathrm{Cl}$, confidence interval; Inf, information; Sim, similarities; Arit, arithmetic; Voc, vocabulary; Comp, comprehension; DS, digit span; PC, picture completion; Cod, coding; PA, picture arrangement; BD, block design; OA, object assembly; SS, symbol search; Maz, mazes.

had already had an earlier clinical diagnosis of ADHD, and 22 had clear symptoms consistent with ADHD (Diagnostic and Statistical Manual of Mental Disorders, fourth edition ${ }^{17}$ ), according to their current school reports, the interview data (parents' and pupils' own information), the cognitive assessment, and the information in school health records.

The difference between fluid and crystallized intelligence was especially large for pupils with ADHD. A $2 \times 2$ analysis of variance with type of intelligence (crystallized/fluid) as a within-subject factor, ADHD diagnosis (yes/no) as a grouping factor, and mean intelligence score as the dependent variable revealed a marginally significant interaction effect

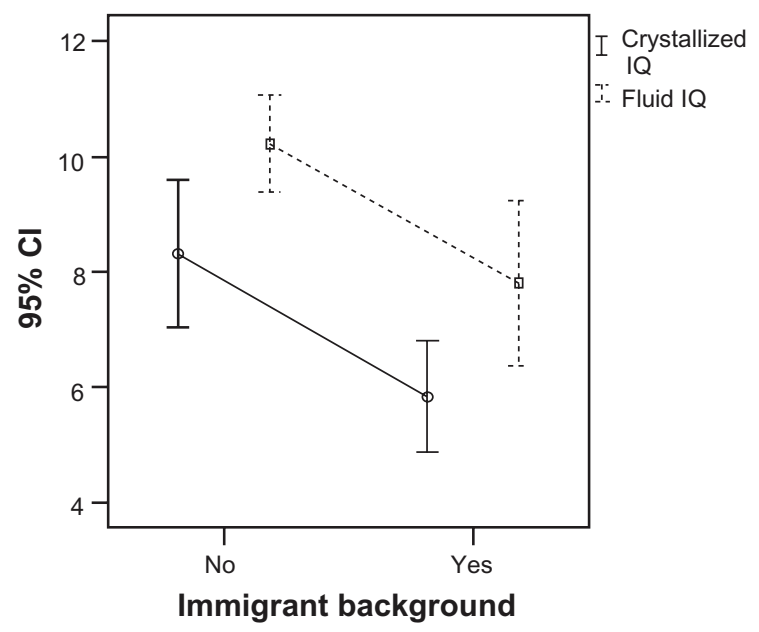

Figure 2 Means and confidence intervals for intelligence scores as a function of type of intelligence and immigrant background.

Abbreviations: $\mathrm{Cl}$, confidence interval; IQ, intelligence quotient. (type of intelligence $\times$ diagnosis; $\mathrm{F}_{1,42}=3.40, P=0.072$, $\eta^{2}=0.075$ ) (Figure 3).

Five of the pupils were determined to have Asperger's syndrome, four of whom had been diagnosed previously, with the other one having been diagnosed with this disorder at a special unit in connection with the reassessment. In another pupil, clear autistic features were found.

One pupil had dyslexia diagnosed at a special unit in connection with the reassessment. One pupil was found to have symptoms consistent with anxiety/depression in the final assessment and was therefore referred to a psychiatric unit. Severe perceptual and cognitive difficulties and an extremely slow cognitive speed were diagnosed in one pupil who had cerebral visual impairment. Another pupil had cognitive problems (mainly autistic features) related to a 22q11 syndrome.

Thus, 43 pupils (96\%) were found to have a neurodevelopmental/neuropsychiatric disorder or clear developmental problems at the end of the study period.

\section{Discussion}

The participants constituted a small sample from a large cohort of adolescents who did not qualify for studies at an ordinary senior high school in Sweden. They represented 45 individuals, each with their own specific history, who had not succeeded within the ordinary school system, this being their common denominator. Four of them were found to have cognitive deficits corresponding to mild ID, but the others had general cognitive abilities within the normal variation. Three of these had BIF according to the cognitive assessment conducted in conjunction with this study. This cognitive



Figure 3 Means and confidence intervals for intelligence scores as a function of type of intelligence and ADHD diagnosis.

Abbreviations: ADHD, attention deficit/hyperactivity disorder; $\mathrm{Cl}$, confidence interval; IQ, intelligence quotient. 
weakness is associated with considerable consequences for school success. ${ }^{18}$

A majority of the pupils $(n=26)$ had major attention deficits consistent with ADHD, but only four of them had had their specific disabilities recognized during primary school. Despite having a mean IQ within the normal range $(\mathrm{M}=89.3)$, they had not succeeded in school and had not attained the prescribed learning outcomes. They had failed early, and many had dropped out of school for long periods of time.

Twenty-four pupils had not been assessed before this project started. Thirteen of them had reported school problems already in the first, second, or third school year, and another four during the fourth year at school. We can only speculate on why these pupils had not been properly assessed before: explanations such as speech and language impairments or having an immigrant background masking more general cognitive problems could clarify why certain pupils had slipped through the net. The "wait and see" philosophy seemed to be a factor in several cases, and may have resulted in too long a wait for adequate measures and interventions to be taken. Social disadvantages, trauma, and other environmentally acquired conditions may also be given as the ultimate explanation for a person's shortcomings. The concept of "double hazards," implying that a child may be exposed to both cognitive deficits and insufficient social support, must also be highlighted. ${ }^{19}$ Thus, the interaction of environmental factors - supportive as well as adverse - must always be considered.

There are several factors contributing to the low detection rate of developmental problems at school: cognitive deficits underlying behavioral problems are not recognized and identified, social factors are interpreted as being the entire explanation, and the existence of a combination of social and cognitive problems is not sufficiently considered. Moreover, ADHD has many presenting symptoms, some of which could be regarded as comorbidities - anxiety, depression, dyslexia, and general learning problems - and the symptom pattern changes as the child grows older. Gillberg ${ }^{20}$ has drawn attention to the fact that there is a need for many cases to be considered from a multidisciplinary view in order to capture the complete situation.

We have no systematic data on preschool symptoms in our group of participants; however, many pupils are likely to have had developmental problems at that time. The concept of early symptomatic syndromes eliciting neurodevelopmental clinical examination (ESSENCE) ${ }^{20}$ highlights the existence of early symptoms and points out the necessity of a broad, close, and active collaboration among professionals to take action to help these children at an early age.
Frazier et $\mathrm{al}^{8}$ have cited a number of studies indicating that persons with ADHD are at risk of encountering several different types of academic failure, such as failing to pass exams, high rates of grade retention, and increased occurrence of learning difficulties. Breslau et $\mathrm{al}^{6}$ studied the impact of attention problems and internalizing and externalizing behavior at school entry on academic achievement at the end of high school. Only attention problems predicted academic outcome at the age of 17 . They stated, “... this finding ... [supports] the conclusion that among a variety of childhood behavior problems, attention problems are the principal predictor of diminished achievement relative to expectations on the basis of a child's cognitive ability."

The concepts of crystallized and fluid intelligence were originally developed by Horn and Cattell ${ }^{21}$ to describe two of the major functions in intellectual performance, among several others. Crystallized intelligence is thought to be acquired through problem solving and the learning of facts through schooling and environmental influence. This index reflects a general fund of knowledge that can be used when solving new and more advanced problems.

The majority of pupils in our study had already demonstrated learning and/or attention difficulties in Grade 1. We speculate that their insufficient learning in the early grades hampered their ability to acquire the basic skills necessary to build higher-level reading, writing, and mathematical skills.

Conversely, fluid intelligence was higher than crystalline intelligence for the pupils under investigation, and for pupils with ADHD it was considerably higher (this latter relationship was only marginally significant). Fluid intelligence represents an ability to solve problems through basic reasoning, which is an ability that does not primarily depend on formal schooling. This index is mainly based on nonverbal subtests, and is thus more "culture free." The finding indicated that the ability of the youngsters to conduct logical reasoning and solve problems that do not require "school knowledge" was good. Intelligence or cognitive capacity is not unidimensional; humans use unique types of thinking, reasoning, and problem solving when facing different situations.

The finding that pupils with an immigrant background had lower scores on both crystallized and fluid intelligence could be due to a number of reasons that have nothing to do with their immigrant status. We speculate that the finding could be due to a selection bias. Having an immigrant background, and therefore often using a different language in school than at home, may be seen as an explanation for a child's shortcomings in school and can mask more 
general cognitive problems. Thus, a pupil with an immigrant background asking for or being referred for assessment might make for a more problematic situation.

This study definitely had its limitations. First, the study group was small and not population based. We cannot claim that the group that was investigated was representative in a broader sense, ie, representing the majority of pupils not succeeding in school. However, the history of each pupil and their current cognitive function was thoroughly assessed, and a systematic review of their school and social situation was performed. A certain proportion of pupils enlisted in this type of program do not attend school at all. Those are probably the pupils with even more severe difficulties. Their situation has to our knowledge not been studied.

The unnecessary academic failure of any child is a tragedy. Our overriding aim was to study and present a group of young persons who had not succeeded in school, to present their background, to assess their current developmental status, and to discuss what could be learned from their history. The findings point to the following considerations. If our school system was fully aware of the impact of BIF and of attention deficits on school failure, many children could receive a better-adapted school situation. There is a need for collaboration at different levels: on a global level between neurodevelopmental medicine/ neuropsychiatry/neuropsychology and representatives from special education. On an individual level, these children need close collaboration between school health staff - and ESSENCE teams when needed - and those responsible for the planning of education at school. Pedagogy does not exist in isolation, but is heavily based on neuropsychology. We need screening and identification of children who present symptoms that could interfere with their academic achievement, and we need to develop educational methods - and use them - to help more pupils to succeed at school.

Since there can be a significant negative impact of limited educational opportunities on future socioeconomic outcomes, the question of who is at risk is important, both for affected individuals and more generally for public health.

\section{Acknowledgments}

The authors are grateful to school doctor/psychiatrist Eva Lindberg for her valuable cooperation, especially in the case conferences. The study was partly financed by the Centre for Competence in Treatment and Care (CKVO), based in Stockholm University.

\section{Disclosure}

The authors report no conflicts of interest in this work.

\section{References}

1. Zambrano-Sánchez E, del Consuelo Martínez-Wbaldo M, Poblano A. Risk factor frequency for learning disabilities in low socioeconomic level preschool children in Mexico City. Rev Lat Am Enfermagem. 2010;18(5):998-1004.

2. Sayal K, Owen V, White K, Merrell C, Tymms P, Taylor E. Impact of early school-based screening and intervention programs for ADHD on children's outcomes and access to services: follow-up of a schoolbased trial at age 10 years. Arch Pediatr Adolesc Med. 2010;164(5): 462-469.

3. Desai PP, Mohite P. An exploratory study of early intervention in Gujarat state, India: pediatricians' perspectives. J Dev Behav Pediatr. 2011;32(1):69-74.

4. Reinke WM, Herman KC, Petras H, Ialongo NS. Empirically derived subtypes of child academic and behavior problems: co-occurrence and distal outcomes. J Abnorm Child Psychol. 2008;36(5):759-770.

5. Bakare MO, Ubochi VN, Ebigbo PO, Orovwigho AO. Problem and pro-social behavior among Nigerian children with intellectual disability: the implication for developing policy for school based mental health programs. Ital J Pediatr. 2010;36:37.

6. Breslau J, Miller E, Breslau N, Bohnert K, Lucia V, Schweitzer J. The impact of early behavior disturbances on academic achievement in high school. Pediatrics. 2009;123(6):1472-1476.

7. Valtonen R, Ahonen T, Tolvanen A, Lyytinen P. How does early developmental assessment predict academic and attentional-behavioural skills at group and individual levels? Dev Med Child Neurol. 2009;51(10): 792-799.

8. Frazier TW, Youngstrom EA, Glutting JJ, Watkins MW. ADHD and achievement: meta-analysis of the child, adolescent, and adult literatures and a concomitant study with college students. J Learn Disabil. 2007;40(1):49-65.

9. Carroll JM, Maughan B, Goodman R, Meltzer H. Literacy difficulties and psychiatric disorders: evidence for comorbidity. J Child Psychol Psychiatr. 2005;46(5):524-532.

10. Barkley RA. Major life activity and health outcomes associated with attention-deficit/hyperactivity disorder. J Clin Psychiatry. 2002; 63 Suppl 12:10-15.

11. Hinshaw SP. Academic underachievement, attention deficits, and aggression: comorbidity and implications for intervention [review]. J Consult Clin Psychol. 1992;60(6):893-903.

12. Swedish National Agency for Education. Press release. November 15, 2010. Swedish.

13. Ek U, Westerlund J, Holmberg K, Fernell E. Academic performance of adolescents with ADHD and other behavioural and learning problems - a population-based longitudinal study. Acta Paediatr. 2011;100(3):402-406.

14. Wechsler D. Wechsler Intelligence Scale for Children. 3rd ed, revised. New York: Psychological Corporation; 1999.

15. Wechsler D. Wechsler Adult Intelligence Scale (WAIS-III). Stockholm, Sweden: Psykologiförlaget; 2003.

16. Raven JC. Manual for Raven's Progressive Matrices and Vocabulary Scales. London, UK: HK Lewis; 1977.

17. American Psychiatric Association (APA). Diagnostic and Statistical Manual of Mental Disorders. 4th ed. Washington DC: APA; 1994.

18. Fernell E, Ek U. Borderline intellectual functioning in children and adolescents - insufficiently recognized difficulties. Acta Paediatr. 2010;99:748-753.

19. Escalona SK. Babies at double hazard: early development of infants at biological and social risk. Pediatrics. 1982;70:670-676.

20. Gillberg C. The ESSENCE in child psychiatry: Early Symptomatic Syndromes Eliciting Neurodevelopmental Clinical Examinations. Res Dev Disabil. 2010;31(6):1543-1551.

21. Horn JL, Cattell RB. Refinement and test of the theory of fluid and crystallized intelligences. J Educ Psychol. 1966;57(5): 253-270. 
Clinical Audit

\section{Publish your work in this journal}

Clinical Audit is an international, peer-reviewed, open access journal focusing on the processes and outcomes of clinical audit in any area of healthcare. All aspects of patient care are addressed within the journal and practitioners from all disciplines are invited to submit their work. Areas covered include: Publication of audits; How an audit has changed practice;

Submit your manuscript here: http://www.dovepress.com/clinical-audit-journal
Dovepress

Practical tips on how to do audits and to avoid pitfalls; How audits have changed patient care; Calls and justifications for new audits. The manuscript management system is completely online and includes a very quick and fair peer-review system, which is all easy to use. Visit http://www.dovepress. com/testimonials.php to read real quotes from published authors. 